\title{
RITUXIMAB COMO TERAPIA AUXILIAR PARA PÚRPURA TROMBOCITOPÊNICA TROMBÓTICA REFRATÁRIA AO TRATAMENTO COM PLASMAFÉRESE: RELATO DE CASO
}

\author{
RITUXIMAB AS ADJUVANT THERAPY FOR THROMBOTIC \\ THROMBOCYTOPENIC PURPURA REFRACTORY TO TREATMENT \\ WITH PLASMAPHERESIS: CASE REPORT
}

DOI: $10.5380 /$ rmu.v1i1.40684

Marcelo Murilo Mejia', Gustavo Lenci Marques', Felipe Dunin dos Santos', Alessandra Medeiros Rodrigues Soares', Caroline Cunha Bernardi', João Samuel de Holanda Farias', Francisco Luis Gomide Mafra Magalhães ${ }^{1}$

\section{RESUMO}

O tratamento de escolha para a púrpura trombocitopênica trombótica, um transtorno na agregação plaquetária com hemólise desordenada e oclusão de microvasculatura, consiste em plasmaférese e uso de corticosteroides. No entanto, há casos refratários a essa terapêutica, e o Rituximab, um anticorpo monoclonal anti-CD20, parece ser uma alternativa. Relatamos o caso de uma paciente de 35 anos, com quadro de sangramento e comprometimento neurológico, que foi submetida a plasmaférese e evoluiu com instabilidade hemodinâmica. Após tentativa sem sucesso e piora do quadro, foi administrado Rituximab $375 \mathrm{mg} / \mathrm{m}^{2}$, associado a plasmaférese. Evoluiu com melhora clinica e laboratorial. O Rituximab parece ser uma opção aos casos de PTT refratária, porém estudos randomizados e controlados ainda são ne-cessários para estabelecer melhor seu papel.

Palavras chave: Púrpura trombocitopênica trombótica, rituximab, plasmaférese.

\section{ABSTRACT}

The treatment of choice for thrombotic thrombocytopenic purpura, a disorder in platelet aggregation with inordinate hemolysis and microvascular occlusion, consists of plasmapheresis and corticosteroids. However, there are cases refractory to this therapy and Rituximab, a monoclonal anti-CD20 antibody appears to be an alternative. We report a case of a 35-year-old woman with signs of bleeding and neurological impairment, who underwent plasmapheresis, and after developed hemodynamic instability. After trying plasmapheresis without success, Rituximab was administered $375 \mathrm{mg} / \mathrm{m}^{2}$, associated with plasmapheresis. She evolved with clinical and laboratory improvement. Rituximab appears to be an option in cases of refractory TTP, but randomized controlled trials are still needed to better establish its role.

Key-words: Thrombotic thrombocytopenic purpura, rituximab, plasmapheresis.

\author{
1-Universidade Federal do Paraná \\ Contato do Autor / Mail to: \\ Marcelo Murilo Mejia - m_mejia@hotmail.com \\ Rua General Carneiro, 181 - Alto da Glória Curitiba - PR, 80060-900, 10 Andar, Departamento de Clínica Médica
}




\section{INTRODUÇÃO}

A púrpura trombocitopênica trombótica (PTT) é uma emergência hematológica caracterizada por uma desordem da agregação plaquetária que resulta na hemólise de hemácias, consumo de plaquetas e oclusão de microvasculatura - o que se traduz em febre, trombocitopenia, anemia hemolítica microangiopática, desordens neurológicas e renal ${ }^{1,2,3,4}$. A sua patogênese está relacionada a deficiência do ADAMTS13, uma protease clivadora do fator de von-Willebrand $d^{2,3,4}$. A taxa de mortalidade é de aproximadamente $20 \%^{5}$. 0 manejo inicial inclui plasmaférese e esteróides. 0 objetivo deste relato é aumentar a base de dados já existente sobre o uso de Rituximab, um anticorpo monoclonal contra o antígeno $C D 20$ das células $B^{3,4,6}$, como terapia eficaz e nos pacientes com PTT que respondem inadequadamente ao tratamento padrão.

\section{RELATO DO CASO}

Paciente de 35 anos, feminina, branca, católica, admitida no PA-HC, com queixa de astenia há 1 mês, tendo evoluído em duas semanas com equimoses difusas pelo corpo, associado a quadro de icterícia. Apresentava quadro de menometrorragia, há cerca de 1 mês antes do internamento. Posteriormente, teve sintomas de parestesia à direita associada à síncope e confusão mental. Na época, negava sangramento grastrointestinal, gengivorragia e epistaxe, ou febre. No dia prévio ao internamento, apresentou quadro de hematúria e quatro episódios de êmese, além de redução da diurese desde então.

$\mathrm{Na}$ admissão, estava em regular estado geral, confusa em tempo e espaço, hipocorada +++/IV, acianótica, ictérica +/IV, desidratada. Glasgow 14. Ao exame segmentar apresentou mucosas hipocoradas e icterícia em escleras, petéquias em palato, sopro sistólico ++/IV (pancardíaco), dor a palpação profunda de abdome, porém sem sinais de irritação peritoneal ou visceromegalias. Laboratório descrito na tabela 1. Como a paciente apresentava plaquetopenia associada a anemia hemolítica com esquizócitos, e alterações neurológicas, seu diagnóstico foi PTT com indicação imediata de plasmaferese. Apresentou sibilância, lesões urticariformes pruriginosas, hipotensão, bradicardia e dessaturação $\left(\right.$ satO $_{2}=88 \%$ ) após a primeira sessão de plasmaférese, sendo submetida a inalação com berotec e atrovent, além da administração de $100 \mathrm{mg}$ de hidrocortisona e 1 ampola de Benadryl ${ }^{\circledR}$. As sessões de plasmaférese prosseguiram, sem melhora do quadro. Após uma semana da sua internação, houve piora do quadro neurológico e o serviço de Hematologia orientou o inicio de Vincristina ${ }^{\circledR} 2 \mathrm{~g}$ EV e Ciclosporina, tendo sido realizada somente a primeira. No dia seguinte, com a piora do nível de consciência, foi realizado Rituximab
$375 \mathrm{mg} / \mathrm{m}^{2}$. Dia 28/07 teve melhora discreta do nível de consciência. Até o dia 02/08 manteve a plasmaferese, em um total de 13 sessões. Dia 03/08 foi submetida a nova dose de Rituximab, e teve alta no dia 04/08 com $194.000 / \mathrm{mm}^{3}$ plaquetas, sem alterações neurológicas ou outras queixas.

Tabela 1: Exames laboratoriais

\begin{tabular}{|c|c|c|c|c|c|}
\hline & \multicolumn{2}{|c|}{ ADMISSÄO } & \multicolumn{2}{|l|}{ ALTA } \\
\hline VG & $\mathrm{Hb}$ & 17,9 & 5,8 & 31 & 10 \\
\hline Leuc & Bastões & 6980 & 20 & 11010 & 0 \\
\hline \multicolumn{2}{|c|}{ Plaquetas } & \multicolumn{2}{|c|}{$7000 / \mathrm{mm}^{3}$} & \multicolumn{2}{|c|}{$1940000 / \mathrm{mm}^{3}$} \\
\hline \multicolumn{2}{|c|}{ Esquizócitos } & \multicolumn{2}{|c|}{++} & \multicolumn{2}{|c|}{ - } \\
\hline$\overline{B T}$ & BD & 3,64 & 1,29 & 0,6 & 0,22 \\
\hline \multicolumn{2}{|l|}{ LDH } & \multicolumn{2}{|l|}{1895} & \multicolumn{2}{|l|}{439} \\
\hline \multicolumn{6}{|c|}{ 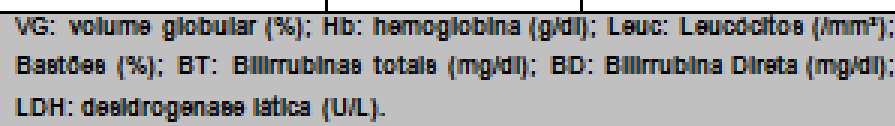 } \\
\hline
\end{tabular}

\section{DISCUSSÃO}

A terapia padrão para a PTT com plasmaférese melhora o prognóstico e induz a remissão em mais de $90 \%$ dos casos. O que se discute, entretanto, é o tratamento e a prevenção das recorrências da doença, que são comuns ${ }^{7}$. Rituximab é provavelmente a melhor opção para os casos severos e recorrentes, e há evidência que esta droga induz a remissão, ainda que o tempo de sua extensão seja desconhecido ${ }^{1,3,7}$. O mecanismo de ação proposto é o clearance das células B CD20+ que produzem anticorpos anti-ADAMTS13 ${ }^{4}$.

Entre os benefícios dessa terapia, destacam-se um tempo de resposta mais curto, alta porcentagem de pacientes com remissão, e mais rápido aumento na atividade do ADAMTS13 ${ }^{3}$. O diagnóstico pós-natal de RVU geralmente é feito após a ocorrência de infecção de trato urinário ou, mais raramente, durante o rastreamento de crianças descendentes de famílias com altas taxas de RVU.

Os métodos de imagem mais utilizados para o diagnóstico pós-natal de RVU são a ultrassonografia de rins e vias urinárias, cistografia com radionuclídeos e uretrocistografia miccional. Este último é o melhor exame diagnóstico, sendo o único que permite graduar o RVU e detectar a presença de refluxo intra-renal.

CONCLUSÃO 
Em consonância com a atual literatura, a paciente apresentou benefício na utilização desta droga associada a terapia com plasmaférese $e^{1,2,4}$. Estudos com controle de remissão a longo prazo em pacientes que foram submetidos a esta modalidade de tratamento ainda são necessários, para definição da dose adequada, tempo e sucesso do esquema.

\section{REFERÊNCIAS BIBLIOGRÁFICAS}

1. KIVITY S; AGMON-LEVIN N; Rituximab for Thrombotic Thrombocytopenic Purpura. Israel Medical Association Journal, Is-rael, v.13, p.436-437, jul.2011

2. MONTOYA RC, POIESZ BJ; Rituximab as prophylaxis in chronic relapsing thrombotic thrombocytopenic purpura: a case report and review of the literature. Blood Coagulation and Fibrinolysis, NY (USA), v. 23, p.338-441, fev.2012

3. SHAH N, SARODE R; Thrombotic Thrombocytopenic Purpura What is New? Journal Of Clinical Apheresis, Dallas, TX, p. 30-35. 19 fev. 2013.

4. IIOKA F et AL; Short and long-term effects of rituximab for the treatment of thrombotic thrombocytopenic purpura: four case reports. Int J Hematol, Japan. 10 ago. 2012.

5. KESSLER CS, KHAN BA, LAI-MILLER K; TRHOMBOTIC THROMBOCYTOPENIC PURPURA: A HEMATOLOGICAL EMERGENCY. The Journal of Emergency Medicine. USA, p.1-7, jan.2012. 